\title{
A Theoretical Study of the Scalability of a Sonicated Continuous Crystallizer for the Production of Aspirin
}

\author{
Symeon V. Savvopoulos, ${ }^{\dagger, \ddagger}$ Mohammed N. Hussain, ${ }^{\dagger, \ddagger}$ Tom Van Gerven, ${ }^{\dagger}$ and \\ Simon Kuhn ${ }^{* \dagger}$ \\ $\dagger K U$ Leuven, Department of Chemical Engineering, Celestijnenlaan 200F, 3001 Leuven, \\ Belgium \\ $\ddagger$ Equal contribution \\ E-mail: simon.kuhn@kuleuven.be
}

Phone: +321632 2718

\begin{abstract}
Ultrasound is frequently applied in crystallization to enhance nucleation and achieve crystal sizes within a narrow range. In this work, a mathematical model is developed which couples the acoustic effect of ultrasound on the antisolvent crystallization of aspirin with the flow hydrodynamics and associated micromixing. In the first step, a qualitatively validated $3 \mathrm{D}$ acoustic simulation of the crystallizer is used to understand the acoustic field in the reactor. Following this an assessment of various flow and micromixing models is carried out using a 3D CFD model which is compared to a previously validated $1 \mathrm{D}$ model. The identified models successfully capture the acoustic field and predict the crystal size and the crystals' coefficient of variation in experimental studies. The proposed model offers a practical platform that can be applied to experiments for improving the design of continuous crystallizers, as the model has
\end{abstract}


the ability to predict the crystal production at larger scales to optimize the antisolvent crystallization of aspirin.

\section{Introduction}

Crystallization is one of the most widely used unit operations in the process industries as it is applied to produce, recover, or purify solids from a continuous liquid or gas phase. ${ }^{1}$ Although it is found in the vast majority of chemical processes under some form, some notable applications include agricultural products, specialty chemicals, and pharmaceutical drugs. ${ }^{1}$ Despite being widely used in a range of industries, crystallization is a complex process, involving multiphase equilibria, multiple kinetic phenomena, and polymorphism.

Crystallization processes can be performed in batch, semi-batch, or as a continuous process, but they are most often applied in a batch process form in the industry. Batch crystallization makes economical sense for small production capacities and for high value materials such as pharmaceuticals. However, batch crystallization does have some drawbacks, with the common limitations being the difficulty in controlling the heat and mass transfer processes, which are the physical principles that control the whole set of crystal characteristics and batch-to-batch variations. ${ }^{2}$ The most important crystal properties are the mean crystal size and the crystal size distribution (CSD), which determine how the final product behaves. The drawbacks of batch crystallization led researchers and industry initiatives to explore continuous processing technology, which enables the maintenance of higher product standards. ${ }^{3}$ This work focuses on one of the most-used drugs, aspirin (acetylsalicylic acid - ASA). As for continuous processes, they allow for more control over process parameters due to their lower operating volume. They also operate at steady state, meaning that they don't suffer from fluctuations in their operating conditions, which translates to a more homogeneous product over time compared to batch processing. Also, they provide the ability to produce particles with specific particle sizes and smaller particle size distribution (PSD), along with control 
over other properties like polymorphism. ${ }^{4}$ Plug flow crystallizers produce quantities on demand, while the use of raw materials can be minimized as their equipment is small. ${ }^{5}$ They are also capable of being scaled up faster compared to batch systems. ${ }^{2}$ Another technology important to crystallization is ultrasound. Low frequency ultrasound is used for improving continuous crystallization processes as the generated cavitation bubbles act as nucleation sites, forming crystals with small size and a narrower CSD ${ }^{6-9}$ Flow based devices in which ultrasound has been applied are slug flow crystallizers, ${ }^{10}$ droplet-based crystallizers,${ }^{11}$ plug flow, ${ }^{12}$ and millichannels. ${ }^{13,14}$ In addition to the potential nucleation enhancing effect of the cavitation bubbles, they can also break larger crystals during their collapse. ${ }^{15,16}$ In addition to this, secondary nucleation can be enhanced from crystal fragments due to ultrasound cleavage, and the increased fluid shear can form new nuclei from an existing crystal. ${ }^{16,17}$ The crystal shape can also be affected by the application of ultrasound. A significant example is the case of benzoic acid, whose crystal shape is hexagonal under sonication instead of needle shape in silent conditions. ${ }^{18}$ Lastly, the cavitation bubbles generated by ultrasound enhance the micromixing in the system, which becomes homogeneous with small variations in supersaturation. ${ }^{19}$

Crystallization processes can be described theoretically by population balance models (PBMs) as they capture the nucleation and the growth of crystals over time. ${ }^{20}$ Hence, mathematical modelling with PBMs is applied to tubular crystallizers, ${ }^{21}$ and mixed suspension mixed product removal (MSMPR) crystallizers under silent conditions ${ }^{22}$ or with ultrasound. ${ }^{15}$ Computational fluid dynamics (CFD) can be combined with PBMs to include hydrodynamic effects in the description of the crystallization process, and therefore this approach can contribute to the scale-up of the continuous crystallizers. ${ }^{23,24}$ In the case of antisolvent crystallization of aspirin, the effect of ultrasound causes complex flow phenomena in the system. Understanding these phenomena, and modelling them are crucial for further scale-up. The nucleation and growth rates as well as the solubility and their dependence on process temperature and antisolvent content has been previously validated. ${ }^{21}$ Thus, a model 
for the ultrasound-assisted antisolvent crystallization has to capture the acoustic field, the proper fluid flow model which describes the phenomena of ultrasound, the energy balance of the system, ${ }^{25}$ and the PBMs of the crystallization.

The high fidelity crystallization model of aspirin has been validated previously, and it could capture the sonicated lab-scale continuous crystal production, including all heat transfer phenomena that occur and might affect the process. ${ }^{19,26}$ The overall objective of this article is to develop and validate a CFD model for the ultrasound-assisted continuous antisolvent crystallization of aspirin for scale-up. Diverging from previous mathematical models for the continuous antisolvent crystallization of aspirin, ${ }^{26}$ this article presents the first tubular crystallizer model that (1) considers a validated acoustic field in the reactor generated by the ultrasound transducer, (2) takes into consideration the proper fluid flow model (laminar

or turbulent with micromixing), (3) uses validated expressions of solubility, nucleation, and growth rates, and (4) predicts the crystal growth in the presence of ultrasound in a scaled-up reactor. This study aligns with the ongoing efforts for optimizing continuous crystallization processes.

\section{Mathematical Model}

As shown in Fig. 1, the lab-scale experimental setup consists of a tubular crystallizer and an ultrasound transducer which operates at $24 \mathrm{~W}$ and at $42 \mathrm{kHz}$ is bolted underneath the crystallizer (Ultrasonics World ${ }^{\complement}$ MPI-7850D-20 40 60H). Antisolvent crystallization occurs within the channels in the crystallizer under sonication. ${ }^{19,26}$ Temperature control of the process is provided by a constant cooling water flow. Crystal sizes are measured offline and at steady state conditions. The chamber's dimensions are 80 x 80 x $10 \mathrm{~mm}^{3}$, its plexiglass top has dimensions of $80 \times 80 \times 6 \mathrm{~mm}^{3}$ and the volume for cooling water has dimensions of $60 \times 60 \times 10 \mathrm{~mm}^{3}$.

The mathematical model of the ultrasound-assisted continuous antisolvent crystalization 


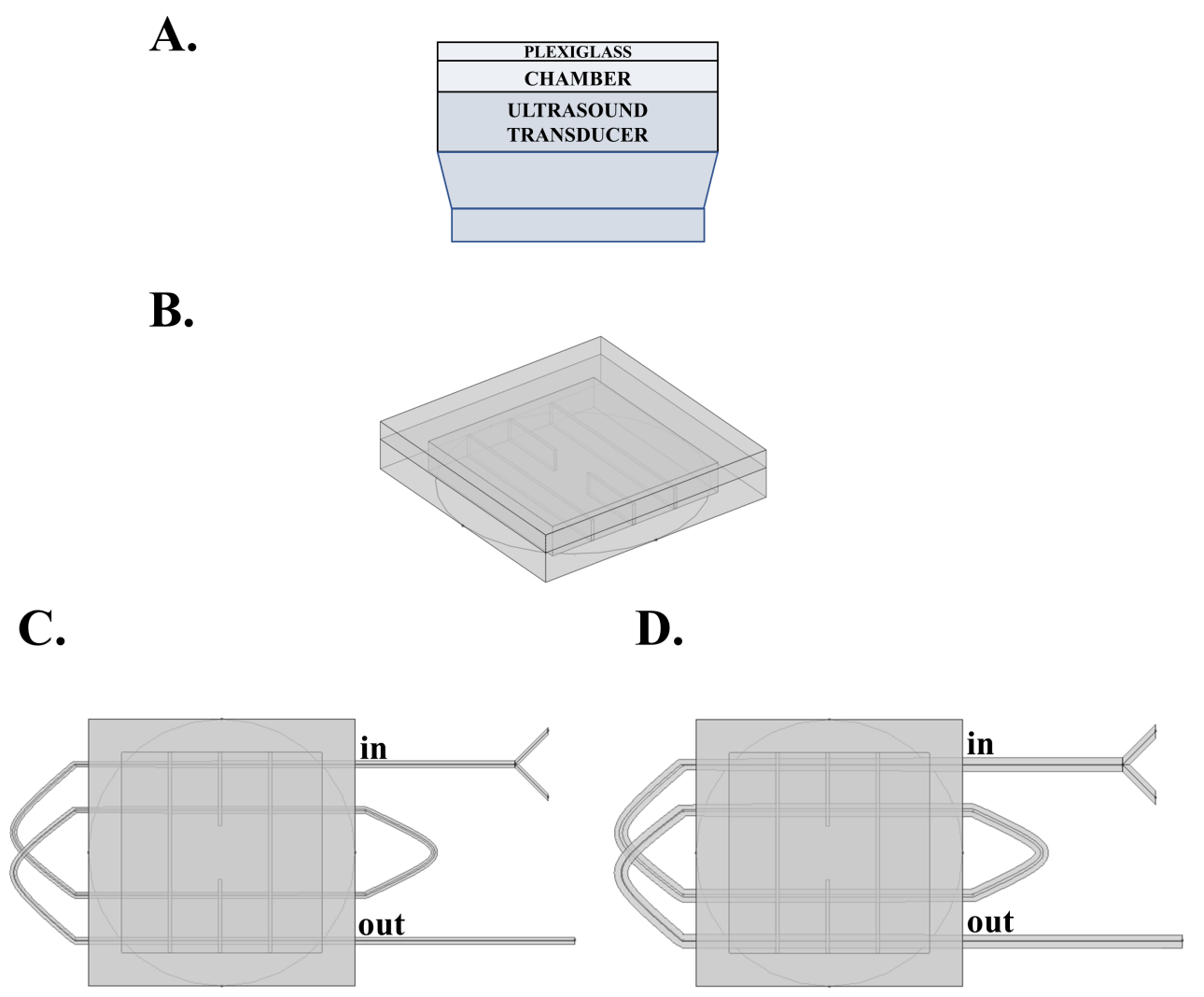

Figure 1: Experimental setup. A) the three main layers of the experimental setup, B) the chamber where the transducer is at the bottom (cycle), and its plexiglass in the top, C) experimental setup with a tubular reactor of $2 \mathrm{~mm}$, D) experimental setup with a tubular reactor of $4 \mathrm{~mm}$ (in and out denote the inlet and the outlet of the transducer chamber).

of aspirin in a tubular reactor consists of the following group of equations: a) acoustic pressure in the reactor and in the reactor channel with the Helmholtz equation, ${ }^{27}$ b) the flow profile, ${ }^{28} \mathrm{c}$ ) the transport of species, ${ }^{28} \mathrm{~d}$ ) the population density of the crystals, ${ }^{26}$ and e) the energy balance. ${ }^{26}$ The CFD model has been developed using the commercial software COMSOL v5.5. The tube diameters as well as their contacting angle upstream of the reactor have been captured to mimic the actual flow field. The contact point of the transducer and the reactor was modelled as a circular face through which the driving pressure is dissipated. The entire reactor assembly was discretized in approximately 2,500,000 domain elements, 140,000 boundary elements, and 7,700 edge elements using the COMSOL Meshing tool (Fig. 2). The mean cell volume is $0.05 \mathrm{~mm}^{3}$. The solver used for solving the equations is MUMPS (MUltifrontal Massively Parallel Sparse direct Solver). 
A.

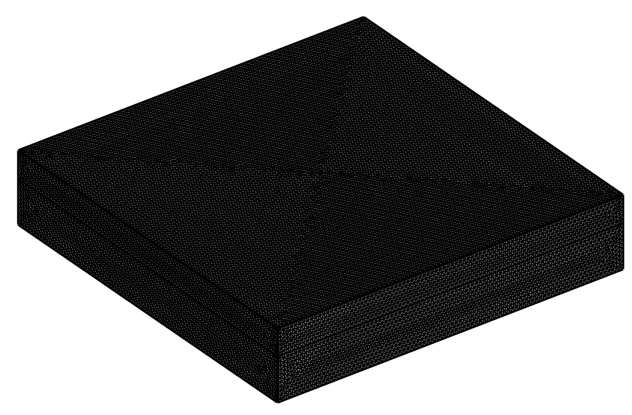

B.

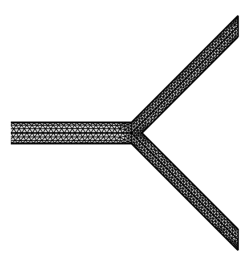

C.

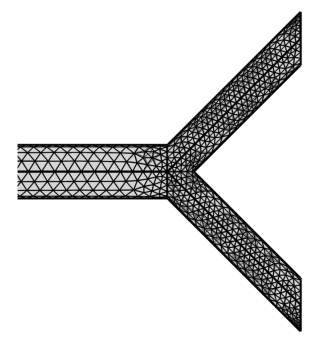

Figure 2: Mesh. A) Chamber of the transducer, B) y-mixer part of tubular reactor of $2 \mathrm{~mm}$ (enlarged), C) y-mixer part of tubular reactor of $4 \mathrm{~mm}$ (enlarged)

\subsection{Acoustic pressure}

The acoustic pressure in the reactor is obtained by solving

$$
\nabla\left(\frac{1}{\rho_{G}} \nabla \hat{p}\right)+\left(\frac{\omega^{2}}{\rho_{G} C_{G}^{2}}\right)=0
$$

where $\hat{p}$ is the acoustic pressure amplitude $[\mathrm{Pa}], \omega$ is the frequency $\left[\mathrm{s}^{-1}\right], \rho_{G}$ is the density of the materials which are aluminium, water and plexiglass $\left[\mathrm{kg} \cdot \mathrm{m}^{-3}\right]$, and $C_{G}$ is the speed of sound $\left[\mathrm{m} \cdot \mathrm{s}^{-1}\right]$.

The acoustic pressure at the transducer dissipating surface is

$$
P_{\text {trans }}=\sqrt{\frac{2 \rho_{B} C_{B} P_{\text {diss }}}{A_{\text {trans }}}}
$$

where $\rho_{B}$ is the bulk density $\left[\mathrm{kg} \cdot \mathrm{m}^{-3}\right], C_{B}$ is the speed of sound $\left[\mathrm{m} \cdot \mathrm{s}^{-1}\right], P_{\text {diss }}$ is the driving power of the transducer $(24 \mathrm{~W})$, and $A_{\text {trans }}$ is the irradiating surface area of the transducer $\left[\mathrm{m}^{2}\right]$.

The acoustic pressure in the channel which also accommodates the bubble related wave attenuation is

$$
\nabla^{2} \hat{p}+\left(k_{m}^{2}\right) \hat{p}=0
$$


where $k_{m}^{2}$ is the complex wave number, and $k_{m}^{2}$ equals

$$
k_{m}^{2}=\frac{\omega^{2}}{C^{2}}\left(1+\frac{4 \pi C_{l i q}^{2} n_{b} R_{0}}{\omega_{0}^{2}-\omega^{2}+2 i b \omega}\right)
$$

where $C_{l i q}$ is the speed of sound in the liquid $\left[\mathrm{m} \cdot \mathrm{s}^{-1}\right], R_{0}$ is the equilibrium radius $(\approx$ $3 / f), n_{b}$ is the number of bubbles, $b$ is the damping factor and $\omega_{0}$ is the resonant frequency of the bubbles $\left[\mathrm{rad} \cdot \mathrm{s}^{-1}\right]$.

This resonant frequency is calculated as

$$
\omega_{0}^{2}=\frac{p_{0}}{\rho R_{0}^{2}}\left(\operatorname{Re} \Phi-\frac{2 \sigma}{R_{0} p_{0}}\right)
$$

where $\sigma$ is the surface tension of the liquid $[\mathrm{N} \cdot \mathrm{m}]$ and $p_{0}$ is the undisturbed pressure in the bubble $[\mathrm{Pa}]$, calculated as

$$
p_{0}=p_{l i q}+\frac{2 \sigma}{R_{0}}
$$

The complex dimensionless parameter $\Phi$ equals

$$
\Phi=\frac{3 \gamma_{f}}{1-3\left(\gamma_{f}-1\right) i \chi\left[\sqrt{\left(\frac{i}{\chi}\right)} \operatorname{coth}\left(\frac{i}{\chi}\right)-1\right]}
$$

where $\gamma_{f}$ is the adiabatic factor.

The dimensionless parameter $\chi$ equals

$$
\chi=\frac{D_{g a s}}{\omega R_{0}^{2}}
$$

where $D_{\text {gas }}$ is the thermal diffusivity of the gas $\left[\mathrm{m}^{2} \cdot \mathrm{s}^{-1}\right]$.

The damping factor equals

$$
b=\frac{2 \mu}{\rho R_{0}^{2}}+\frac{p_{0}}{2 p \omega R_{0}^{2}} \operatorname{Im} \Phi+\frac{\omega^{2} R_{0}}{2 C}
$$


where $\mu$ is the viscosity of the medium $[\mathrm{Pa} \cdot \mathrm{s}]$.

The cavity volume fraction can be approximated as

$$
\beta \approx 2 \cdot 10^{-9} \hat{p} \quad \forall p_{G, \text { Blake }}<\hat{p}<1 \cdot 10^{8} \mathrm{~Pa}
$$

\section{$2.2 \quad$ Hydrodynamics}

The effect of ultrasound induced cavitation results in complex flow regimes. In this work, we assume two distinct possibilities: 1) laminar flow and 2) turbulent flow. These simulated flow cases are coupled to the PBM to have an end point validation of the crystal sizes. The assumption of turbulent flow is based on the fact that cavitation bubbles generate intense micromixing owing to their movement and associated phenomena, e.g. shock waves.

The governing equations are given by the conservation of mass and momentum, which are the continuity equation

$$
\frac{\partial \rho}{\partial t}+\nabla \cdot(\rho \vec{u})=0
$$

where $\vec{u}$ is the velocity vector $\left[\mathrm{m} \cdot \mathrm{s}^{-1}\right]$, and $\rho$ is the density $\left[\mathrm{kg} \cdot \mathrm{m}^{-3}\right]$, and in the laminar flow approach the Navier-Stokes equations

$$
\frac{\partial}{\partial t}(\rho \vec{u})+\nabla \cdot(\rho \vec{u} \vec{u})=-\nabla p+\nabla \cdot(\overline{\bar{\tau}})+\rho \vec{g}
$$

where $\tau$ is the stress tensor $\left[\mathrm{kg} \cdot \mathrm{m}^{-1} \mathrm{~s}^{-2}\right]$, and $p$ is the hydrodynamic pressure $[\mathrm{Pa}]$. The no-slip $(\vec{u}=0)$ boundary condition is applied at the walls.

In the turbulent flow approach, the Reynolds-averaged Navier-Stokes equations, and the standard $k-\epsilon$ turbulence model are used.

$$
\frac{\partial}{\partial t}(\rho \vec{u})+\nabla \cdot(\rho \vec{u} \vec{u})=-\nabla p+\nabla \cdot(\overline{\bar{\tau}})+\rho \vec{g}
$$




$$
\begin{gathered}
\frac{\partial}{\partial t}(\rho k)+\nabla \cdot(\rho k \vec{u})=\nabla \cdot\left[\left(\mu+\frac{\mu_{t}}{\sigma_{k}}\right) \nabla \cdot k\right]+G_{k}-\rho \epsilon+S_{k} \\
\frac{\partial}{\partial t}(\rho \epsilon)+\nabla \cdot(\rho \epsilon \vec{u})=\nabla \cdot\left[\left(\mu+\frac{\mu_{t}}{\sigma_{\epsilon}}\right) \nabla \cdot \epsilon\right]+C_{1 \epsilon} \frac{\epsilon}{k} G_{k}-C_{2 \epsilon} \rho \frac{\epsilon^{2}}{k}+S_{\epsilon}
\end{gathered}
$$

where $\epsilon$ is the turbulent kinetic energy dissipation rate $\left[\mathrm{m}^{2} \cdot \mathrm{s}^{-2}\right], k$ is the turbulent kinetic energy $\left[\mathrm{m}^{2} \cdot \mathrm{s}^{-2}\right], G_{k}$ is the rate of deformation. $C_{1 \epsilon}, C_{2 \epsilon}, \sigma_{k}$, and $\sigma_{\epsilon}$ are adjustable constants. The values of the adjustable constants are $1.44,1.92,1.00$, and 1.30 , respectively. ${ }^{29} \mu_{t}$ is the eddy viscosity, and is equal to

$$
\mu_{t}=\rho C_{\mu} \frac{k^{2}}{\epsilon}
$$

with $C_{\mu}=0.09 .^{29}$

\section{$2.3 \quad$ Species transport}

In laminar flow, the transport of species is governed by

$$
\frac{\partial C}{\partial t}+\nabla \cdot(C \vec{u})-\nabla \cdot(D \nabla C)=R_{c}
$$

where $C$ is the concentration $\left[\mathrm{kg} \cdot \mathrm{m}^{-3}\right]$, and $R_{c}$ is the consumption rate $\left[\mathrm{kg} \cdot \mathrm{m}^{-3} \cdot \mathrm{s}^{-1}\right]$.

In case of turbulent flow, the micromixing model equations are used. In the micromixing model, there are $N_{e}$ different probability modes or environments in each computational cell in the CFD grid. Therefore, the probability density function (PDF) is discretized into a finite number of delta functions.

$$
f_{\phi}(\psi ; \mathbf{x}, t)=\sum_{n=1}^{N_{e}} p_{n}(\mathbf{x}, t) \prod_{\alpha=1}^{N_{s}} \delta\left[\psi_{\alpha}-\left\langle\phi_{\alpha}\right\rangle_{n}(\mathbf{x}, t)\right]
$$

where $f_{\phi}$ is the joint of all scalars, $N_{s}$ is the number of all species, $p_{n}$ is the volume fraction of environment $n$, and $\left\langle\phi_{\alpha}\right\rangle_{n}$ is the average composition of a scalar $\alpha$ in the environment $n$. 
The weighted concentration is calculated as

$$
\langle s\rangle_{n}=p_{n}\langle\phi\rangle_{n}
$$

The transport of species in an inhomogeneous environment is

$$
\begin{gathered}
\frac{\partial \mathbf{p}}{\partial t}+\nabla \cdot(\mathbf{p} \vec{u})-\nabla \cdot\left(D_{t} \nabla \mathbf{p}\right)=\mathbf{G}(\mathbf{p})+\mathbf{G}_{\mathbf{s}}(\mathbf{p}) \\
\frac{\partial\langle\mathbf{s}\rangle_{n}}{\partial t}+\nabla \cdot\left(\langle\mathbf{s}\rangle_{n} \vec{u}\right)-\nabla \cdot\left(D_{t} \nabla\langle\mathbf{s}\rangle_{n}\right)=\mathbf{M}^{n}\left(\mathbf{p},\langle\mathbf{s}\rangle_{1}, \ldots,\langle\mathbf{s}\rangle_{N_{e}}\right)+\mathbf{M}_{\mathbf{s}}^{n}\left(\mathbf{p},\langle\mathbf{s}\rangle_{1}, \ldots,\langle\mathbf{s}\rangle_{N_{e}}\right)+ \\
+p_{n} \mathbf{R}_{\mathbf{c}}\left(\langle\phi\rangle_{n}\right)
\end{gathered}
$$

where $\mathbf{G}$ and $\mathbf{M}^{n}$ are the rates of $\mathbf{p}=\left[p_{1}, p_{2}, \ldots, p_{n}\right]$, and $\langle\mathbf{s}\rangle_{n}$, respectively. Also, $\mathbf{G}_{\mathbf{s}}$ and $\mathbf{M}_{\mathbf{s}}^{n}$ eliminate the spurious dissipation rate in the mixture-fraction-variance transport equation; $\mathbf{R}_{\mathbf{c}}$ is a consumption/source term. $D_{t}$ is the turbulent diffusivity which equals

$$
D_{t}=D+C_{\mu} \frac{k^{2}}{\epsilon}
$$

The following requirements should be satisfied:

$$
\begin{gathered}
\sum_{n=1}^{N} p_{n}=1 \\
\sum_{n=1}^{N} G_{n}(\mathbf{p})=0 \\
\langle\phi\rangle=\sum_{n=1}^{N_{e}} p_{n}\langle\phi\rangle_{n}=\sum_{n=1}^{N_{e}}\langle s\rangle_{n}
\end{gathered}
$$




$$
\sum_{n=1}^{N_{e}} \mathbf{M}_{\mathbf{s}}^{n}\left(\mathbf{p},\langle\mathbf{s}\rangle_{1}, \ldots,\langle\mathbf{s}\rangle_{N_{e}}\right)=0
$$

To capture the crystallization process three environments are defined: Environment 1 contains the solvent with the solute, environment 2 represents the antisolvent, and environment 3 includes the mixture of environments 1 and 2 . The $\mathbf{G}, \mathbf{M}^{n}, \mathbf{G}_{\mathbf{s}}$ and $\mathbf{M}_{\mathbf{s}}^{n}$ terms are given in Table 1. The mixture fraction in environment 1 equals $<\xi_{1}>=1$, and in $2<\xi_{2}>$ $=0 .{ }^{28,30-32}$

Table 1: Right hand side terms of the micromixing model

\begin{tabular}{ccc}
$\begin{array}{c}\text { Model } \\
\text { variables }\end{array}$ & $\mathbf{G}, \mathbf{M}_{n}$ & $\mathbf{G}_{s}, \mathbf{M}_{s}^{n}$ \\
\hline$p_{1}$ & $-\gamma p_{1}\left(1-p_{1}\right)$ & $\gamma_{s} p_{3}$ \\
$p_{2}$ & $-\gamma p_{2}\left(1-p_{2}\right)$ & $\gamma_{s} p_{3}$ \\
$p_{3}$ & $\gamma\left[p_{1}\left(1-p_{1}\right)+p_{2}\left(1-p_{2}\right)\right]$ & $-2 \gamma_{s} p_{3}$ \\
$\langle s\rangle_{n}$ & $\gamma\left[p_{1}\left(1-p_{1}\right)\langle\phi\rangle_{1}+p_{2}\left(1-p_{2}\right)\langle\phi\rangle_{2}\right]$ & $-\gamma_{s} p_{3}\left(\langle\phi\rangle_{1}+\langle\phi\rangle_{2}\right)$ \\
\multicolumn{3}{c}{$\gamma=\frac{\epsilon_{\xi}}{p_{1}\left(1-p_{1}\right)\left(1-\langle\xi\rangle_{3}\right)^{2}+p_{2}\left(1-p_{2}\right)\langle\xi\rangle_{3}^{2}}$} \\
$\gamma_{s}=\frac{2 D_{t}}{\left.\left(1-\langle\xi\rangle_{3}\right)^{2}+\langle\xi\rangle_{3}^{2}\right)} \frac{\partial \xi \xi\rangle_{3}}{\partial x_{i}} \frac{\partial\langle\xi\rangle_{3}}{\partial x_{i}}$ \\
$\left.\epsilon^{\prime 2}\right\rangle=p_{1}\left(1-p_{1}\right)-2 p_{1} p_{3}\langle\xi\rangle_{3}+p_{3}\left(1-p_{3}\right)\langle\xi\rangle_{3}^{2}$ \\
$\epsilon_{\xi}=2\left\langle\xi^{\prime 2}\right\rangle \frac{\epsilon}{k}$
\end{tabular}

\subsection{Crystal population density}

The population density of the crystals along the tubular reactor is given by ${ }^{21}$

$$
\frac{\partial n}{\partial t}+\nabla \cdot(n \vec{u})-\nabla \cdot\left(D_{t} \nabla n\right)+\frac{\partial(G n)}{\partial L}=S(n, L, x, y, z, t)
$$

where $n$ is the number probability density function of crystals in the slurry $\left[\# \cdot \mathrm{m}^{-3} \mathrm{~m}^{-1}\right], t$ represents the time $[\mathrm{s}], G$ is the crystal growth rate $\left[\mathrm{m} \cdot \mathrm{s}^{-1}\right], S$ is a source term, and $L$ is the characteristic crystal length $[\mathrm{m}]$.

In crystallization, the loss term $R_{c}$ equals: 


$$
R_{c}=-3 \rho_{c} K_{v} \int G n L^{2} d L
$$

where $\rho_{c}$ is the crystal density which equals $1400 \mathrm{~kg} \cdot \mathrm{m}^{-3}$, and $K_{v}$ is the volumetric shape factor of a crystal which equals to $1[-]$.

\subsection{Energy balance}

The energy balance for the tubular reactor is ${ }^{33}$

$$
\begin{gathered}
\frac{\partial(\rho E)}{\partial t}+\nabla \cdot[\vec{u}(\rho E+P)]=\nabla \cdot\left[k_{e f f} \nabla T+\left(\overline{\bar{\tau}}_{e f f} \cdot \vec{u}\right)\right]-U_{c} \alpha_{c}\left(T-T_{w}\right)+P_{\text {net }, c a l} \\
E=C_{p} T-\frac{p}{\rho}+\frac{u^{2}}{2}
\end{gathered}
$$

where $k_{\text {eff }}$ is the thermal conductivity $\left[\mathrm{W} \cdot \mathrm{m}^{-1} \cdot \mathrm{K}^{-1}\right], C_{p}$ is the heat capacity $\left[\mathrm{J} \cdot \mathrm{kg}^{-1} \cdot \mathrm{K}^{-1}\right]$, $U_{c}$ is the overall heat transfer coefficient $\left[\mathrm{J} \cdot \mathrm{m}^{-2} \cdot \mathrm{s}^{-1} \cdot \mathrm{K}^{-1}\right], \alpha_{c}$ is the heat transfer area per unit volume $\left(4 / \mathrm{d}_{\text {in }}\right)\left[\mathrm{m}^{2} \cdot \mathrm{m}^{-3}\right], P_{\text {net,cal }}$ is the calorimetric power of ultrasound $\left[\mathrm{W} \cdot \mathrm{m}^{-3}\right]$ taken from our previous work ${ }^{26}$

$$
P_{\text {net,cal }}=66230.5 P_{\text {net }, U S}
$$

where $P_{n e t, U S}$ is the applied ultrasound power $[\mathrm{W}]$.

\subsection{Boundary and Initial Conditions}

The number density $n$, the solute concentrations $C$, and the energy balance are given by partial differential equations (PDE); thus, they are functions of the crystallizer axial position 
$z$ and time $t$. The boundary conditions of Eqs. 27, 28, and 29 are:

$$
\begin{gathered}
n\left(L_{0}, x, y, z, t\right)=\frac{B_{\text {son }}}{G} \\
n_{B C}(L, x, y, z, t)=n_{\text {feed }}(L, t) \\
C_{B C}(x, y, z, t)=C_{\text {sat }} S_{\text {in }} \rho \frac{Q_{\text {solv }}+Q_{\text {anti }}}{Q_{\text {solv }}} \\
T_{B C}(x, y, z, t)=T_{\text {in }}
\end{gathered}
$$

where $B_{\text {son }}$ is the sonicated nucleation rate $\left[\# \cdot \mathrm{m}^{-3} \cdot \mathrm{s}^{-1}\right], L_{0}$ is the nuclei size $[\mathrm{m}]$, in is an inlet, $n_{\text {feed }}$ is the crystal size distribution at the inlet of the crystallizer (which should be known in a seeded crystallization $\left[\# \cdot \mathrm{m}^{-3} \mathrm{~m}^{-1}\right]$, or in a feed supplied slurry from an upstream process), $S_{i n}$ is the supersaturation ratio at the inlet of the transducer chamber, and $C_{\text {sat }}$ is the solubility $\left[\mathrm{kg} \cdot \mathrm{m}^{-3}\right]$. As for the energy balance, $T_{i n}$ is the inlet temperature $[\mathrm{K}]$ whose value is a combination of the temperature of the upstream process, and the heat of mixing between the water and the ethanol. ${ }^{19,25,26}$ In our experiments, the population density and temperature in boundary conditions are, $n_{\text {feed }}=0 \# \cdot \mathrm{m}^{-3} \cdot \mathrm{s}^{-1}$, and $T_{\text {in }}=298 \mathrm{~K}$.

Furthermore, the initial conditions of Eqs. 27, 28, and 29 are:

$$
\begin{gathered}
n(L, x, y, z, 0)=n_{0}(L, x, y, z) \\
C(x, y, z, 0)=C_{0} \\
T(x, y, z, 0)=T_{0}
\end{gathered}
$$


where $n_{0}$ and $C_{0}$ are the initial number probability density function for the CSD and the initial API concentration in the reactor respectively, and $T_{0}$ is the initial temperature. In our experiments, the initial conditions are, $n_{0}=0 \# \cdot \mathrm{m}^{-3} \cdot \mathrm{s}^{-1}, C_{0}=0 \mathrm{~kg} \cdot \mathrm{m}^{-3}$, and $T_{0}=298$ K.

\subsection{Nucleation and Growth Rates}

The supersaturation ratio $S[-]$ is

$$
S=\frac{C_{w}}{C_{s a t}}
$$

where $C_{w}$ is the aspirin concentration in $\left[\mathrm{kg} \cdot \mathrm{kg}^{-1}\right]$, and $C_{\text {sat }}$ is the solubility of the API $\left[\mathrm{kg} \cdot \mathrm{kg}^{-1}\right]$ and more information are included in the work of Savvopoulos et al. ${ }^{26}$

The sonicated nucleation rate consists of the nucleation caused by ultrasound, $B_{u l t r}$ and secondary nucleation, $B_{s e c}$. When $S>1$, the nucleation rate is: ${ }^{26}$

$$
\begin{aligned}
& B_{\text {son }}=B_{u l t r}+B_{\text {sec }} \\
& B_{\text {ultr }}=\left(\hat{p}>p_{G, \text { Blake }}\right) \beta k_{j 1, \text { son }} \exp \left(\frac{k_{j 2, \text { son }}}{R T}\right) \exp \left(-\frac{k_{j 3, \text { son }}}{l n^{2} S}\right) \\
& B_{\text {sec }}=k_{\text {sec }, 1} \exp \left(-k_{\text {sec }, 2} w\right)(S-1)^{2} \mu_{2}
\end{aligned}
$$

where $k_{j 1, \text { son }}\left[\# \cdot \mathrm{m}^{-3} \cdot \mathrm{s}^{-1}\right], k_{j 2, \text { son }}[\mathrm{J} \cdot \mathrm{mol}], k_{j 3, \text { son }}[-], k_{s e c, 1}\left[\# \cdot \mathrm{m}^{2} \cdot \mathrm{s}^{-1}\right]$ and $k_{s e c, 2}[-]$ are all empirical parameters, and $\mu_{2}$ is the second moment of $n\left[\mathrm{~m}^{2} \cdot \mathrm{m}^{-3}\right]$, estimated as:

$$
\mu_{2}=\int L^{2} n d L
$$

The empirical parameters used here affect the evolution of the nucleation rate at different temperatures and supersaturation ratio values. In Eq. 40, the $p_{G, \text { Blake }}$ denotes the local acoustic pressure threshold which enables the nucleation due to the cavitation caused from ultrasound. 
The growth rate when $S>1$ is given by ${ }^{34}$

$$
G=k_{G 1} \exp \left(-\frac{k_{G 2}}{R T}\right)\left(C_{s a t}(S-1)\right)
$$

where $k_{G 1}\left[\mathrm{~m} \cdot \mathrm{s}^{-1}\right]$ and $k_{G 2}\left[\mathrm{~J} \cdot \mathrm{mol}^{-1}\right]$ are empirical parameters that affect the crystal growth rate at different supersaturation ratios $S$ and temperatures $T$.

\subsection{Solution of PBMs}

In order to solve the PDEs of the system dynamically, all the PDEs need to be discretized along the $x_{-}, y_{-}$, and $z$-axis, as well as along the crystal size $L$. This discretization would generate a large number of Ordinary Differential Equations (ODEs) that will make the solution of this system computationally expensive. Instead of discretization, the method of moments is used for their solution. ${ }^{21}$ The $k^{\text {th }}$ moment of the system is defined as

$$
\mu_{k}=\int L^{k} n d L, k=0,1, \ldots, 5
$$

Based on the classical method of moments (MOM), the PDEs can be integrated along the crystal length $L$ by conversion into a set of moment PDEs, and the computational cost is reduced significantly. Using the MOM, the moment transformation of the PDEs into the first five moments are

$$
\frac{\partial \mu_{0}}{\partial t}+\nabla \cdot\left(\mu_{0} \vec{u}\right)-\nabla \cdot\left(D_{t} \nabla \mu_{0}\right)=B_{\text {son }}
$$

$\forall k \in\{1,2, \ldots, 5\}$

$$
\frac{\partial \mu_{k}}{\partial t}+\nabla \cdot\left(\mu_{k} \vec{u}\right)-\nabla \cdot\left(D_{t} \nabla \mu_{k}\right)=k G \mu_{k-1}
$$

Therefore, the volume-based mean crystal size is given by ${ }^{21}$

$$
L_{43}=\frac{\mu_{4}}{\mu_{3}}
$$


and the coefficient of variation is ${ }^{21}$

$$
C V=\sqrt{\left(\frac{\mu_{3} \mu_{5}}{\mu_{4}^{2}}-1\right)}
$$

The volume density distribution is approximated with a lognormal distribution with a mean equal to $\ln \left(L_{43}\right)$ and a standard deviation of $\sqrt{\ln \left(C V^{2}+1\right)} \cdot{ }^{26,35}$

Table 2: Values of applied parameters in the model.

\begin{tabular}{|c|c|c|c|}
\hline Parameter & Symbol & Value & Unit \\
\hline Acoustic frequency & $f$ & 42 & $\mathrm{kHz}$ \\
\hline Ambient liquid hydrodynamic pressure & $p_{l i q}$ & $10^{5}$ & $\mathrm{~Pa}$ \\
\hline Blake threshold & $p_{G, \text { Blake }}$ & $10^{5}$ & $\mathrm{~Pa}$ \\
\hline Bulk liquid density & $p$ & 1000 & $\mathrm{~kg} \cdot \mathrm{m}^{-3}$ \\
\hline Density of plexiglass & $\rho_{G}$ & 1180 & $\mathrm{~kg} \cdot \mathrm{m}^{-3}$ \\
\hline Density of water & $\rho_{W}$ & 1000 & $\mathrm{~kg} \cdot \mathrm{m}^{-3}$ \\
\hline Density of aluminium & $\rho_{A}$ & 2700 & $\mathrm{~kg} \cdot \mathrm{m}^{-3}$ \\
\hline Diameter of the transducer & $d_{\text {trans }}$ & 80 & $\mathrm{~mm}$ \\
\hline Dynamic viscosity & $\mu$ & 0.001 & $\mathrm{~Pa} \cdot \mathrm{s}$ \\
\hline Power applied at the transducers & $P_{d i s s}$ & 24 & $\mathrm{~W}$ \\
\hline Channel diameter & $d_{\text {in }}$ & 2 & $\mathrm{~mm}$ \\
\hline Scaled reactor diameter & $d_{i n}$ & 4 & $\mathrm{~mm}$ \\
\hline Speed of sound in plastic & $C_{G}$ & 1430 & $\mathrm{~m} \cdot \mathrm{s}^{-1}$ \\
\hline Speed of sound in liquid & $C$ & 1430 & $\mathrm{~m} \cdot \mathrm{s}^{-1}$ \\
\hline Liquid surface tension & $\sigma$ & $7.28 \cdot 10^{-2}$ & $\mathrm{~N} \cdot \mathrm{m}^{-1}$ \\
\hline Universal gas constant & $R$ & 8.314 & $\mathrm{~J} \cdot \mathrm{mol}^{-1} \cdot \mathrm{K}^{-1}$ \\
\hline Nucleation empirical parameter 1 & $k_{j 1, \text { son }}$ & $1.150 \cdot 10^{-7}$ & $\# \cdot \mathrm{m}^{-3} \cdot \mathrm{s}^{-1}$ \\
\hline Nucleation empirical parameter 2 & $k_{j 2, \text { son }}$ & 102696 & $\mathrm{~J} \cdot \mathrm{mol}^{-1}$ \\
\hline Nucleation empirical parameter 3 & $k_{j 3, \text { son }}$ & 0.16 & - \\
\hline Growth empirical parameter 1 & $k_{G 1}$ & $3.21 \mathrm{E} \cdot 10^{-4}$ & $\mathrm{~m} \cdot \mathrm{s}^{-1}$ \\
\hline Growth empirical parameter 2 & $k_{G 2}$ & 19652.720 & $\mathrm{~J} \cdot \mathrm{mol}^{-1}$ \\
\hline Secondary nucleation empirical parameter 1 & $k_{s e c, 1}$ & $1.150 \cdot 10^{11}$ & $\# \cdot \mathrm{m}^{-2} \cdot \mathrm{s}^{-1}$ \\
\hline Secondary nucleation empirical parameter 2 & $k_{s e c, 2}$ & 0.0103 & {$[-]$} \\
\hline Temperature of cooling water & $T_{w}$ & 298 & $\mathrm{~K}$ \\
\hline Heat capacity & $C_{p}$ & 4180 & $\mathrm{~J} \cdot \mathrm{kg}^{-1} \cdot \mathrm{K}^{-1}$ \\
\hline Thermal conductivity & $k_{e f f}$ & 0.620 & $\mathrm{~W} \cdot \mathrm{K}^{-1} \cdot \mathrm{m}^{-1}$ \\
\hline Overall heat transfer coefficient & $U_{c}$ & 150 & $\mathrm{~J} \cdot \mathrm{m}^{-2} \cdot \mathrm{s}^{-1} \cdot \mathrm{K}^{-1}$ \\
\hline Gas thermal diffusivity & $D_{\text {gas }}$ & $1.9 \cdot 10^{-5}$ & $\mathrm{~m}^{2} \cdot \mathrm{s}^{-1}$ \\
\hline Adiabatic factor & $\gamma_{f}$ & 1.327 & {$[-]$} \\
\hline
\end{tabular}


Table 3: CFD cases studied a) in the initial setup, and b) in the scaled up setup.

a) Cases at $d_{i n}=2 \mathrm{~mm}$

\begin{tabular}{|c|c|c|c|c|c|}
\hline Case & $\begin{array}{l}\text { Solution flow } \\
\text { rate }\left[\mathrm{mL} \cdot \mathrm{min}^{-1}\right]\end{array}$ & $\begin{array}{l}\text { Antisolvent flow } \\
\text { rate }\left[\mathrm{mL} \cdot \mathrm{min}^{-1}\right]\end{array}$ & Antisolvent [\%] & $\begin{array}{c}\text { Inlet Supersaturation } \\
\text { ratio [-] }\end{array}$ & $\begin{array}{l}\text { Residence } \\
\text { time [s] }\end{array}$ \\
\hline 1 & 2 & 9 & 86.52 & 2.50 & 8.56 \\
\hline 2 & 2 & 6 & 81.06 & 3.61 & 11.78 \\
\hline 3 & 2 & 3 & 67.90 & 2.42 & 18.84 \\
\hline Case & $\begin{array}{l}\text { Solution flow } \\
\text { rate }\left[\mathrm{mL} \cdot \mathrm{min}^{-1}\right]\end{array}$ & $\begin{array}{l}\text { b) Ca } \\
\text { Antisolvent flow } \\
\text { rate }\left[\mathrm{mL} \cdot \mathrm{min}^{-1}\right]\end{array}$ & $\begin{array}{c}\text { es at } d_{i n}=4 \mathrm{~mm} \\
\text { Antisolvent [\%] }\end{array}$ & $\begin{array}{c}\text { Inlet Supersaturation } \\
\text { ratio [-] }\end{array}$ & $\begin{array}{c}\text { Residence } \\
\text { time }[\mathrm{s}]\end{array}$ \\
\hline 1 & 7.3 & 36.71 & 86.48 & 2.50 & 8.56 \\
\hline 2 & 7.3 & 24.7 & 81.09 & 3.61 & 11.78 \\
\hline 3 & 7.5 & 12.5 & 67.90 & 2.42 & 18.84 \\
\hline
\end{tabular}

\section{Results and Discussion}

\section{$3.1 \quad 1 \mathrm{D}$ model}

The high fidelity 1D model was published in Savvopoulos et al., ${ }^{26}$ where the experimental work of Hussain et al. ${ }^{19}$ was used for its validation. The process model includes population balance modeling equations for capturing the crystal growth along the tubular reactor. ${ }^{19,26}$ The RS-HDMR sensitivity analysis varied all the parameters with a certain step, and after sensitivity index estimation showed the most important parameters that should be identified. ${ }^{26}$ The predictability of the model was tested by conducting new experiments. ${ }^{26}$ The maximum likelihood estimator method from gPROMS estimated the significant parameters of the model. ${ }^{36}$ The most important findings are that the empirical expressions developed in our previous work were based on experiments conducted at different conditions, and the heat transfer phenomena during the crystallization were included as well. Therefore, the model with its kinetics is now practical for studying the scale-up of continuous antisolvent crystallization of aspirin under sonication. 


\section{$3.2 \quad 3 \mathrm{D}$ model}

\subsubsection{Qualitative validation of the acoustic field}

A flow crystallizer for aspirin crystallization is modelled which is coupled to an ultrasound transducer to irradiate the flow and improve crystallization. The finite element method model captures the acoustic pressure distribution in the system (Fig. 3). The acoustic pressure varies between the bottom and the top of the system, where acoustic pressure values greater than the specific threshold of $1 \cdot 10^{5} \mathrm{~Pa}$ indicate cavitation and hence ultrasound enhanced nucleation. As long as the first crystals appear and the second moment increases, the cavitation conditions enhance the secondary nucleation as the formed crystals act as nucleation sites in the entire reactor. The simulation results are validated with sonochemiluminescence experiments, for which a $0.03 \mathrm{mM}$ solution of luminol (3-Aminophthalhydrazide, $98 \%$ purity, Fluka Chemicals) in distilled water was made. Sodium hydroxide (Sigma Aldrich) was added to reach a $\mathrm{pH}$ of 12.2. This solution was mixed with $99.8 \%$ pure absolute ethanol (Fischer Scientific) to have a 50:50 mixture of luminol solution and ethanol by volume. The reactor channels were filled with this mixture. The mixture was allowed to stay in the channels after which ultrasound was turned on. Pictures of sonochemiluminescence were obtained with a Nikon D700 camera with $60 \mathrm{~mm}$ lens (aperture 2.8 and ISO Hi2), see Fig. 3. The exposure time was fixed at 5 min to capture even the weakest cavitation zones. All pictures were taken in a completely dark room, and the ultrasound power was set to $24 \mathrm{~W}$ at a frequency of 42 $\mathrm{kHz}$, which are the parameters used in crystallization experiments. Ethanol was added to have similar conditions to crystallization experiments. The circular acoustic pressure areas created with the use of ultrasound in the mixture of solvent and the antisolvent enhance the growth and periodic collapse of cavitation bubbles. The generation rate of the cavitating bubbles depends on the frequency of the ultrasound. Small crystals are formed when the ultrasound frequency applied is low. On the contrary, the crystals are large and similar to silent conditions when the ultrasound frequency is high. ${ }^{37}$ However, the crystal size distri- 
butions do not vary significantly within the range of $30-166 \mathrm{kHz}$ in the low frequencies. ${ }^{37}$ Thus, the frequency was kept constant and did not vary during the studies conducted. In silent conditions, there was no crystallization, which was due to the poor mixing along the tubular crystallizer.

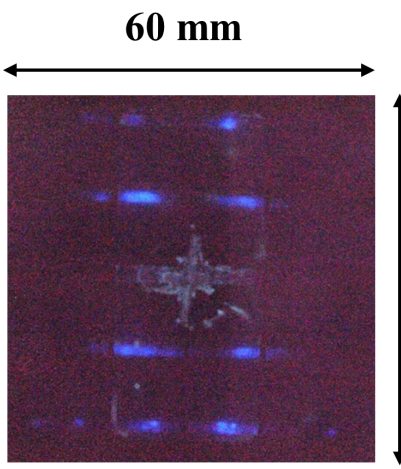

$60 \mathrm{~mm}$

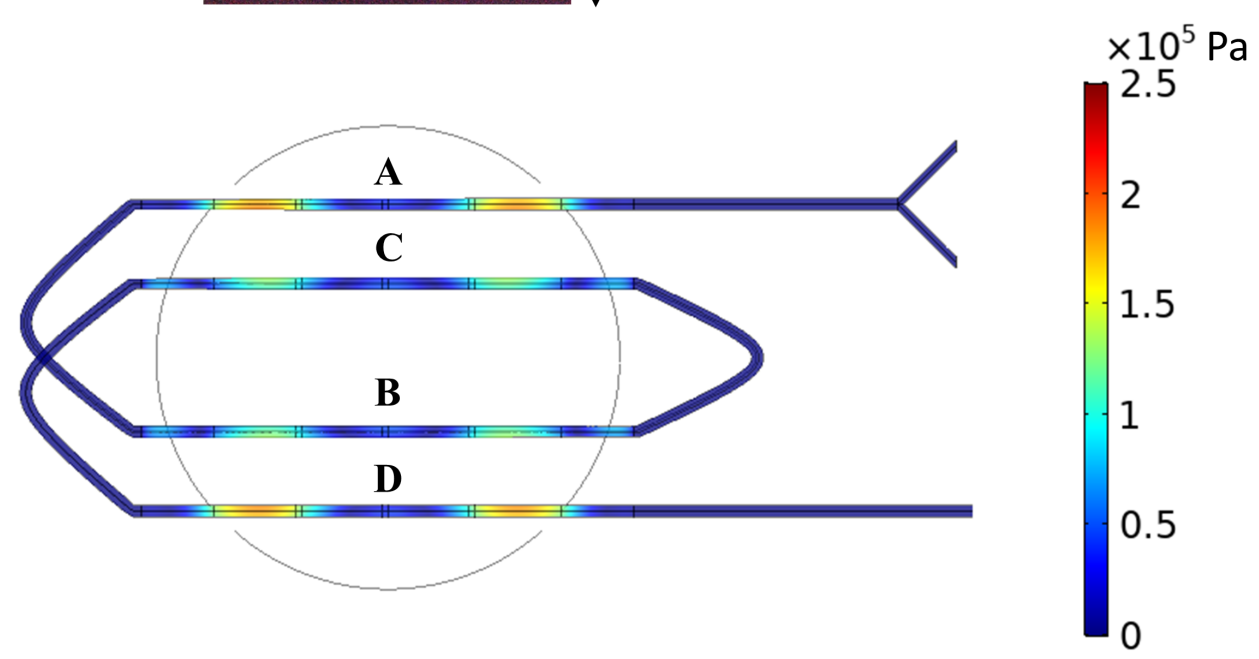

Figure 3: Top: Sonochemiluminescence results at $P_{\text {diss }}=24 \mathrm{~W}, f=42 \mathrm{kHz}$. Bottom: Acoustic pressure field as predicted by the finite element model.

\subsubsection{Selection of the turbulence and micromixing model}

The next step was the coupling of the acoustic field with the crystallization in flow. The collapse of the cavitation bubbles improves the micromixing as long as shockwaves and turbulence are created which disturb the existing flow profile. To capture these effects, the proper flow model should be identified, and in this work we compared laminar flow with turbulent flow and micromixing. As benchmark, we used the case of a reactor with channels 


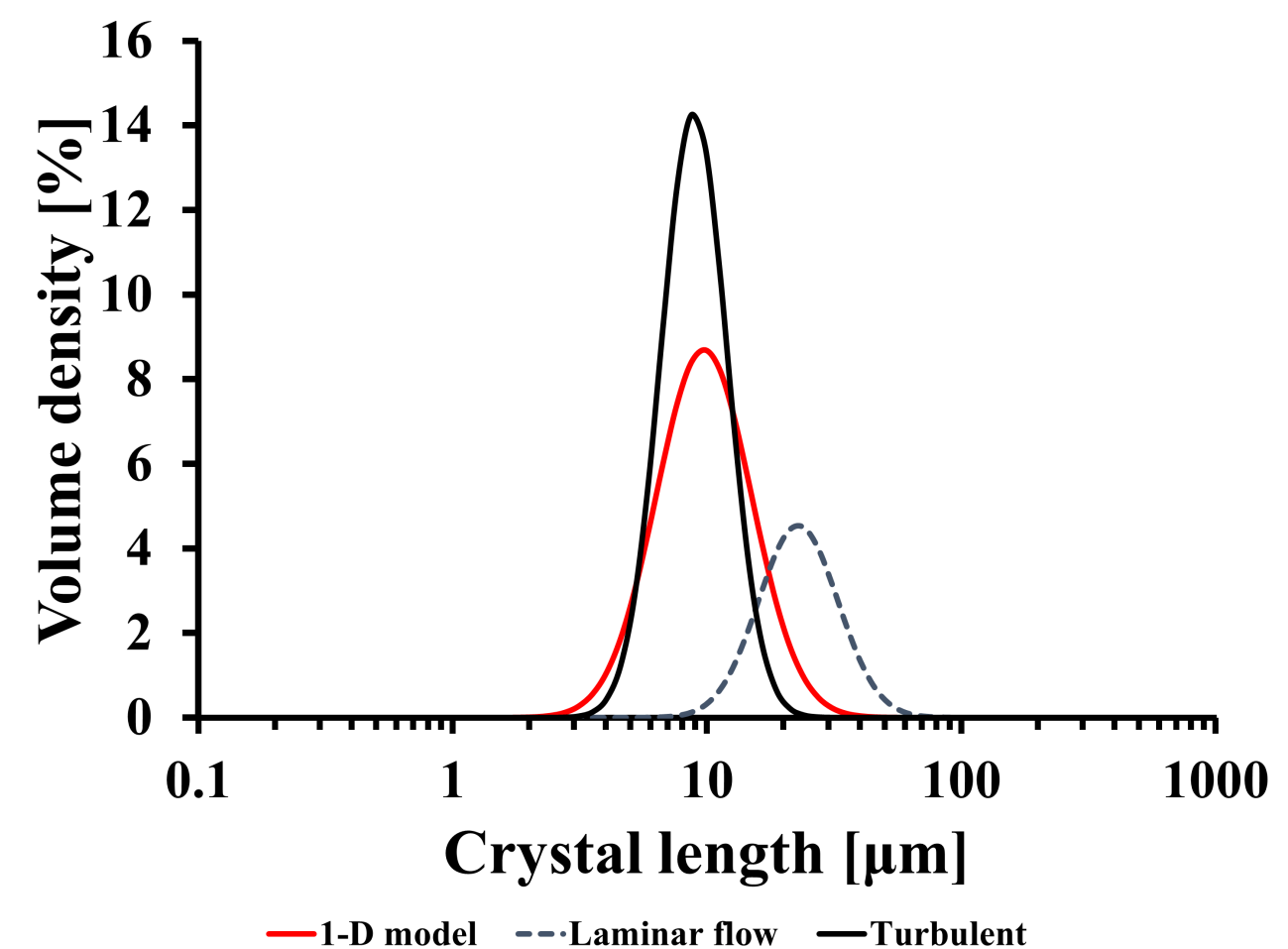

Figure 4: Comparison between the 1D validated model, the CFD model with laminar flow, and the CFD model with turbulent flow and micromixing for a residence time of $8.56 \mathrm{~s}$.

of $2 \mathrm{~mm}$ internal diameter where the antisolvent flow rate equals $9 \mathrm{~mL} \cdot \mathrm{min}^{-1}$ and the flow rate of the solution equals $2 \mathrm{~mL} \cdot \mathrm{min}^{-1} \cdot{ }^{26}$ The total residence time is the shortest and equals around $9 \mathrm{~s}$. The Reynolds number equals 131 indicating laminar flow. However, comparing the crystallization results with that of our previous 1D validated model (Fig. 4 ), it is noticeable that laminar flow does not predict the system adequately. In the 1D well-mixed validated model, the $L_{43}$ equals $11.7 \mu \mathrm{m}$ and CV equals 0.43 . Using laminar flow in $\mathrm{CFD}$, the $L_{43}$ equals $26.0 \mu \mathrm{m}$ and $\mathrm{CV}$ equals 0.36 , while using the turbulent flow with micromixing model, the $L_{43}$, equals $9.73 \mu \mathrm{m}$ and $\mathrm{CV}$ equals 0.3 . Next, the turbulent flow with micromixing model was applied to the longest residence time of $18.84 \mathrm{~s}$, for which the antisolvent flow rate is $3 \mathrm{~mL} \cdot \mathrm{min}^{-1}$ and the solution flow rate is $2 \mathrm{~mL} \cdot \mathrm{min}^{-1}$. Again, the CFD model is in a good agreement with the 1D well-mixed model as it is shown in Fig. 5. Thus, the turbulent flow with micromixing model is able to predict the crystal nucleation and growth in a wide range of residence times. The micromixing model was applied in the 


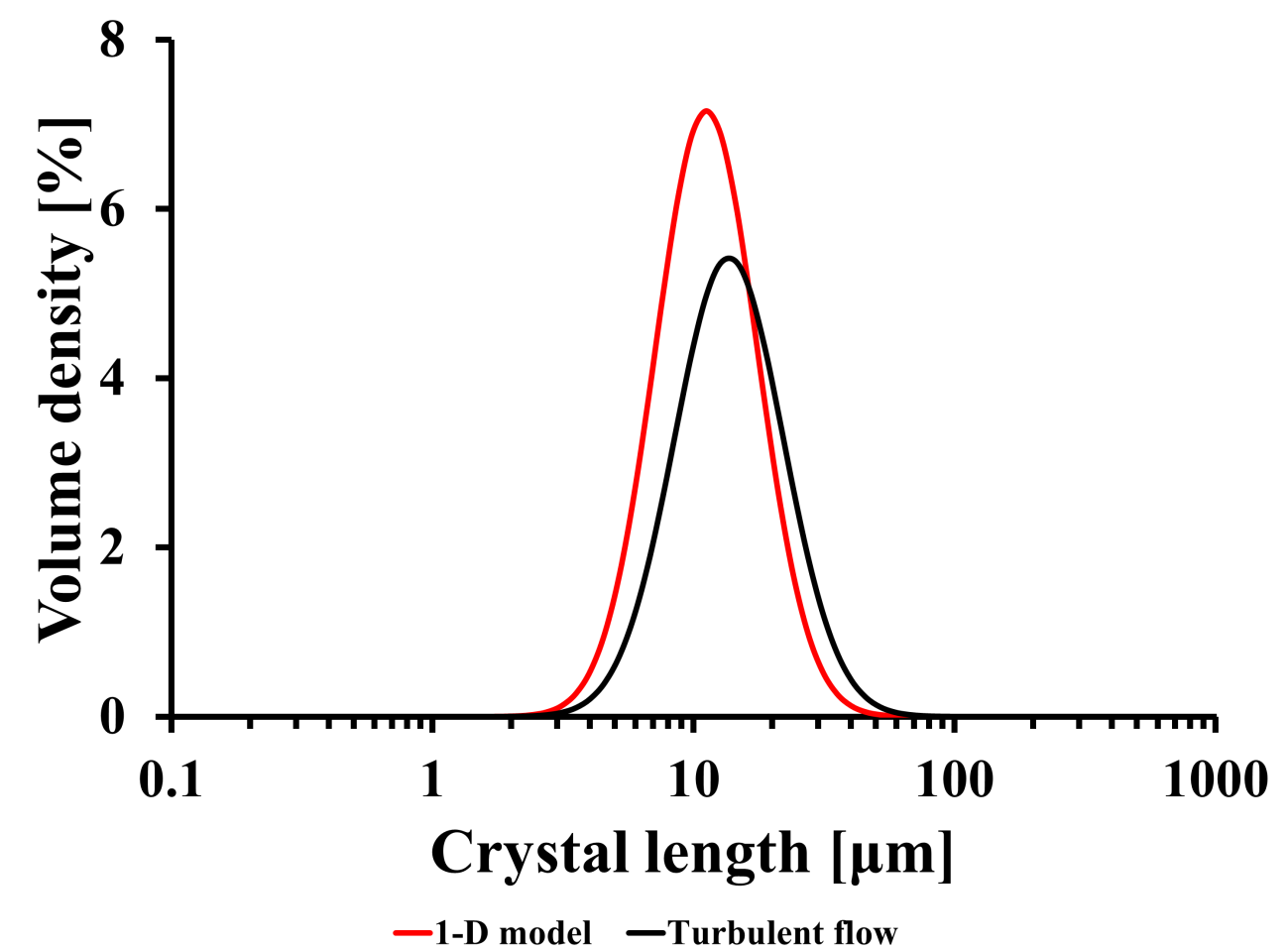

Figure 5: Comparison between the 1D validated model, and the CFD model with turbulent flow and micromixing for a residence time of $18.84 \mathrm{~s}$.

whole area of the channel which is covered by the ultrasound transducer.

As for the crystal sizes observed when using the laminar model, the concentration of the API is lower along the reactor due to the low value of the diffusion coefficient. This event causes the nucleation rate to decrease resulting in more crystal growth. On the contrary, when the nucleation rate is larger, more crystals are produced and they remain small. This behavior is shown in Fig. 4. Apart from the average size and the coefficient of variation of the crystal populations, the addition of the micromixing model is quite critical for simulating the turbulent behavior in the area of the transducer and capturing the experimentally observed crystal sizes.

\subsection{Simulations of a scaled up reactor}

Next, a reactor is considered where the inner diameter of the channel was increased from $2 \mathrm{~mm}$ to $4 \mathrm{~mm}$. The overall reactor dimensions and the ultrasound transducer were kept 


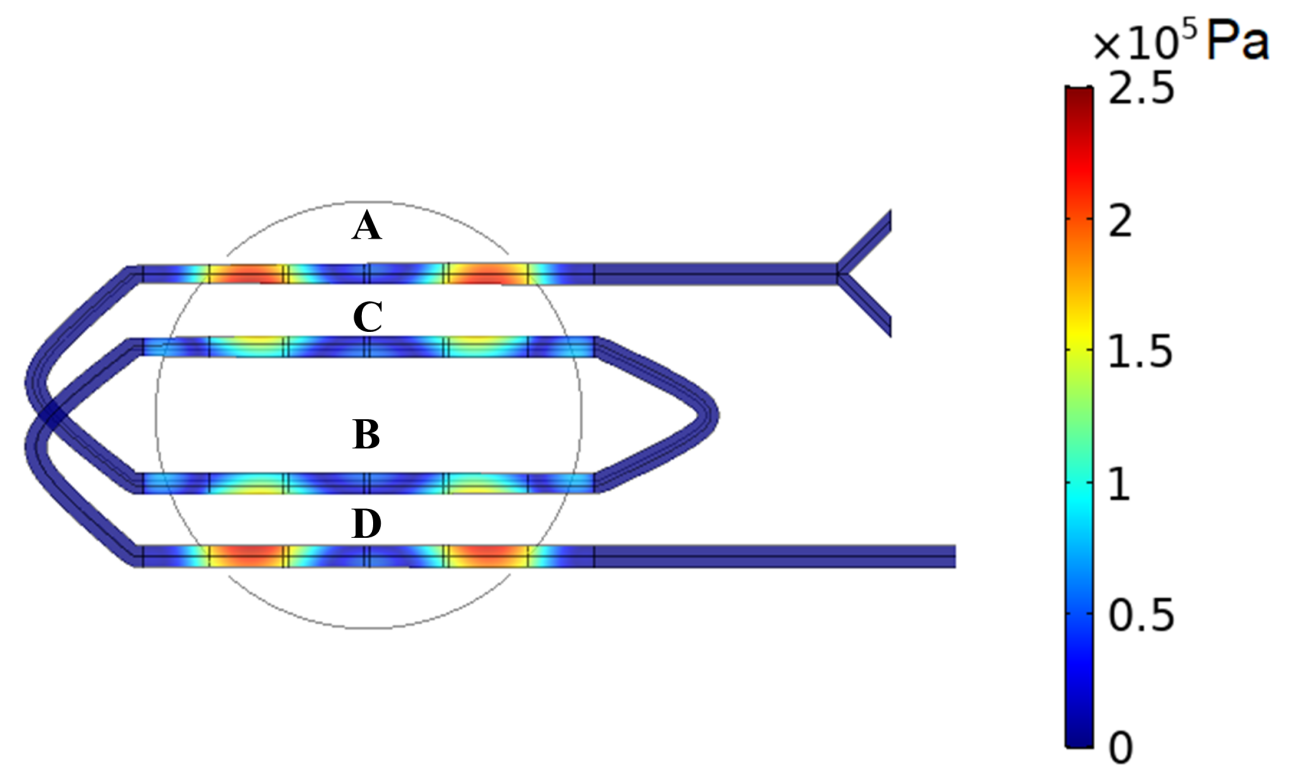

Figure 6: Acoustic field in the scaled system of $4 \mathrm{~mm}$

the same so as to not change the acoustic field, see Fig. 6. The tested cases are shown in Table 3, and in the scaled-up reactor the residence time was maintained and the inlet supersaturation ratio was kept constant. Comparing the resulting crystal sizes between a diameter of $2 \mathrm{~mm}$ and $4 \mathrm{~mm}$ in Figs. $7 \mathrm{~A}-\mathrm{C}$, no significant difference is observed between the two diameters. This can be explained by the fact that the acoustic field is unchanged, and that the ultrasound enhanced mixing enables crystal formation in the beginning as it happens in the $1 \mathrm{D}$ well-mixed system. For the shortest residence time of $8.56 \mathrm{~s}$ the crystal size $L_{43}$ is small, which increases with increasing residence time. This observation also hints at an early nucleation process, so that the growth time of the crystals is approximated by the residence time. Concerning sedimentation, in our work we have increased the flow rate to have the same residence time which is expected to already reduce the chances of sedimentation. In addition to that the action of mixing from ultrasound makes it difficult for sedimentation to occur.

Also the crystal yield is comparable for the three cases between a diameter of $2 \mathrm{~mm}$ and $4 \mathrm{~mm}$, which is depicted in Fig. 8 via the API concentration drop along the crystallizer. However, the productivity increased around three- to four-fold due to the increased volu- 
A.

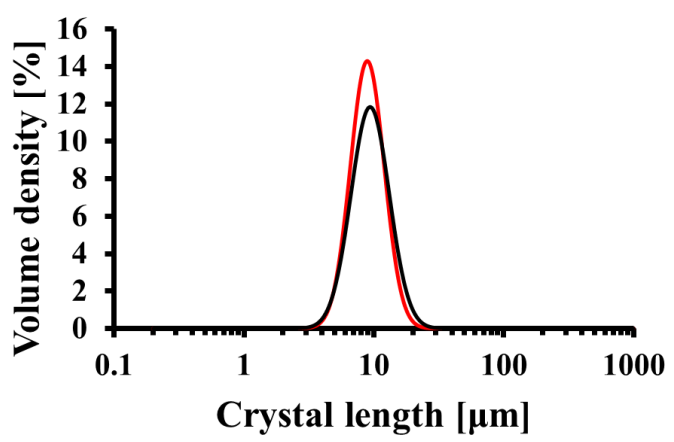

B.

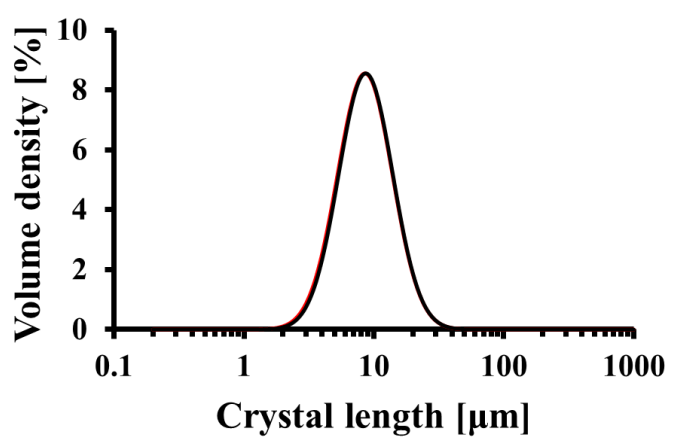

$\longrightarrow d=2 \mathrm{~mm} \longrightarrow \mathrm{d}=4 \mathrm{~mm}$

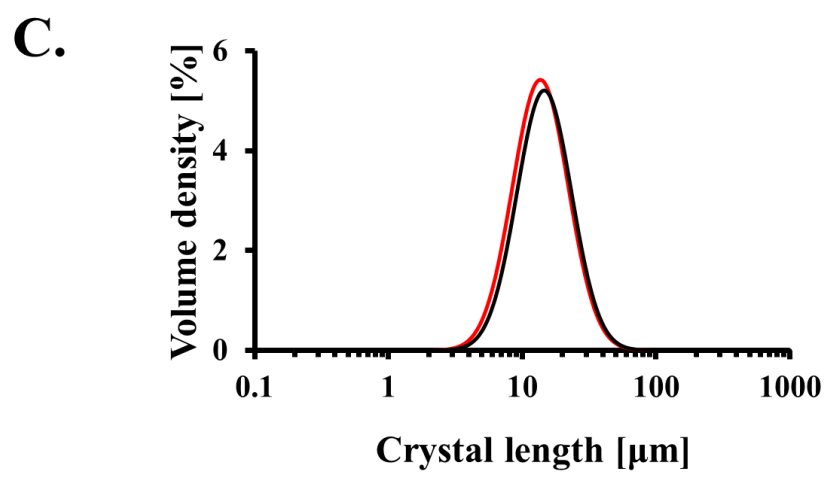

$\longrightarrow \mathrm{d}=2 \mathrm{~mm} \quad \mathrm{~d}=4 \mathrm{~mm}$

Figure 7: A) CSDs of Case 1 (Table 3) when $d_{i n}=2 \mathrm{~mm}\left(Q_{\text {solv }}=2 \mathrm{~mL} \cdot \mathrm{min}^{-1}, Q_{\text {anti }}=9\right.$ $\mathrm{mL} \cdot \mathrm{min}^{-1}, S_{\text {in }}=2.50$, and residence time $\left.8.56 \mathrm{~s}\right)$ and $d_{i n}=4 \mathrm{~mm}\left(Q_{\text {solv }}=7.3 \mathrm{~mL} \cdot \mathrm{min}^{-1}\right.$, $Q_{\text {anti }}=36.71 \mathrm{~mL} \cdot \mathrm{min}^{-1}, S_{\text {in }}=2.50$, and residence time $8.56 \mathrm{~s}$ ), B) CSDs of Case 2 (Table $3)$ when $d_{i n}=2 \mathrm{~mm}\left(Q_{\text {solv }}=2 \mathrm{~mL} \cdot \mathrm{min}^{-1}, Q_{\text {anti }}=6 \mathrm{~mL} \cdot \mathrm{min}^{-1}, S_{\text {in }}=3.61\right.$, and residence time $11.78 \mathrm{~s})$ and $d_{\text {in }}=4 \mathrm{~mm}\left(Q_{\text {solv }}=7.3 \mathrm{~mL} \cdot \mathrm{min}^{-1}, Q_{\text {anti }}=24.70 \mathrm{~mL} \cdot \mathrm{min}^{-1}, S_{\text {in }}=3.61\right.$, and residence time $11.78 \mathrm{~s}$ ), and C) CSDs of Case 3 (Table 3) when $d_{i n}=2 \mathrm{~mm}\left(Q_{\text {solv }}=\right.$ $2 \mathrm{~mL} \cdot \mathrm{min}^{-1}, Q_{\text {anti }}=3 \mathrm{~mL} \cdot \mathrm{min}^{-1}, S_{\text {in }}=2.42$, and residence time $\left.18.84 \mathrm{~s}\right)$ and $d_{\text {in }}=4 \mathrm{~mm}$ $\left(Q_{\text {solv }}=7.5 \mathrm{~mL} \cdot \mathrm{min}^{-1}, Q_{\text {anti }}=12.5 \mathrm{~mL} \cdot \mathrm{min}^{-1}, S_{\text {in }}=2.42\right.$, and residence time $\left.18.84 \mathrm{~s}\right)$. 
metric flow rates in the scaled-up reactor. In our initial setup, the productivity ranged from $116 \mathrm{mg} \cdot \mathrm{min}^{-1}$ to $882 \mathrm{mg} \cdot \mathrm{min}^{-1}$, while in the scaled-up setup the productivity is increased to $554 \mathrm{mg} \cdot \mathrm{min}^{-1}$ to $3,763 \mathrm{mg} \cdot \mathrm{min}^{-1}$.
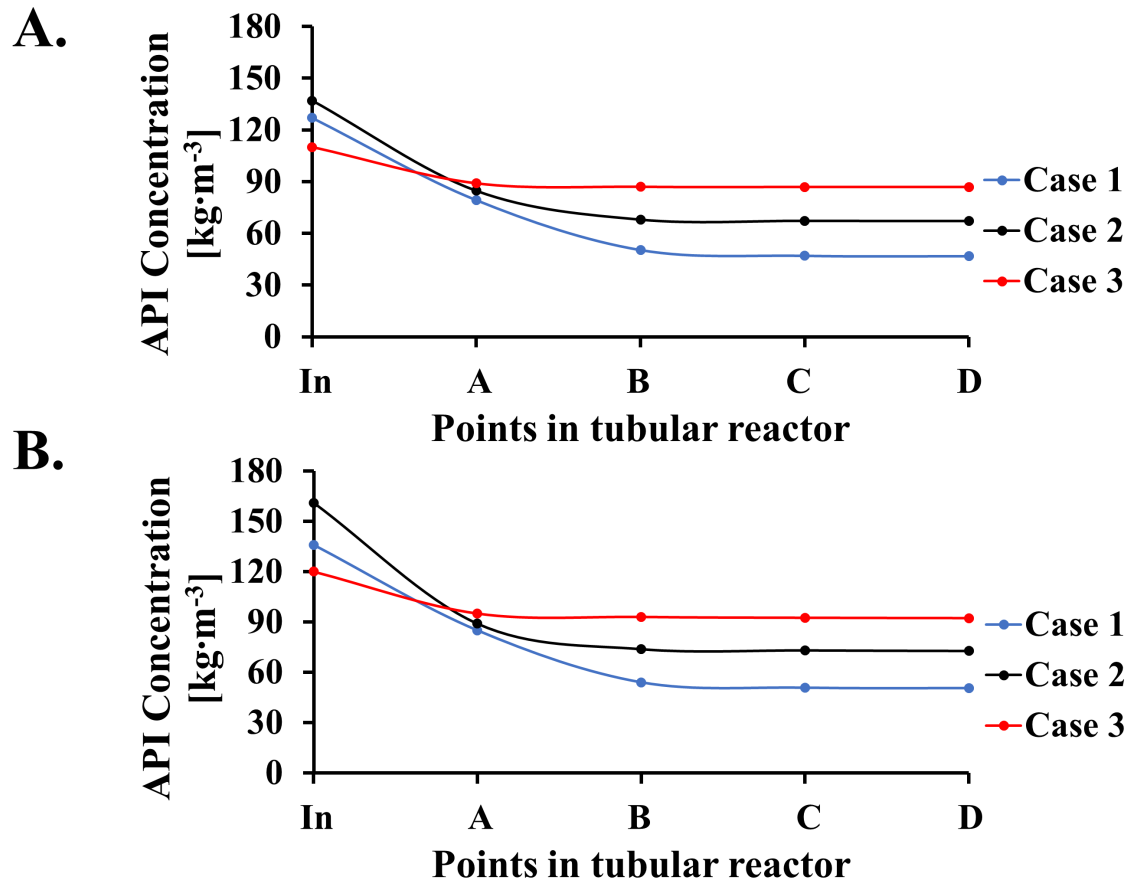

Figure 8: API concentration drop in all cases when A) $d_{i n}=2 \mathrm{~mm}$, and B) $d_{i n}=4 \mathrm{~mm}$. The yields in cases 1, 2, and 3 are in both diameters are $62 \%, 52 \%$, and $22 \%$, respectively.

The mixing efficiency associated with the turbulent conditions occurs due to cavitation. When the antisolvent content is small, the $P_{3}$ value increases faster compared to the case where the antisolvent content is high. Even if the residence time is large, as long as the antisolvent content is lower, the $P_{3}$ increases rapidly and nucleation and growth are activated sooner (Fig. 9).

Our CFD model meaningfully adapts to the experiments conducted during the antisolvent crystallization of water, ethanol, and aspirin. Furthermore, we studied the crystal growth under the acoustic field. The proposed framework has been developed using a variety of assumptions and lab-scale experiments. However, used in tandem with more enlarged crystallizers and different geometries, the developed work may enable dynamic antisolvent 


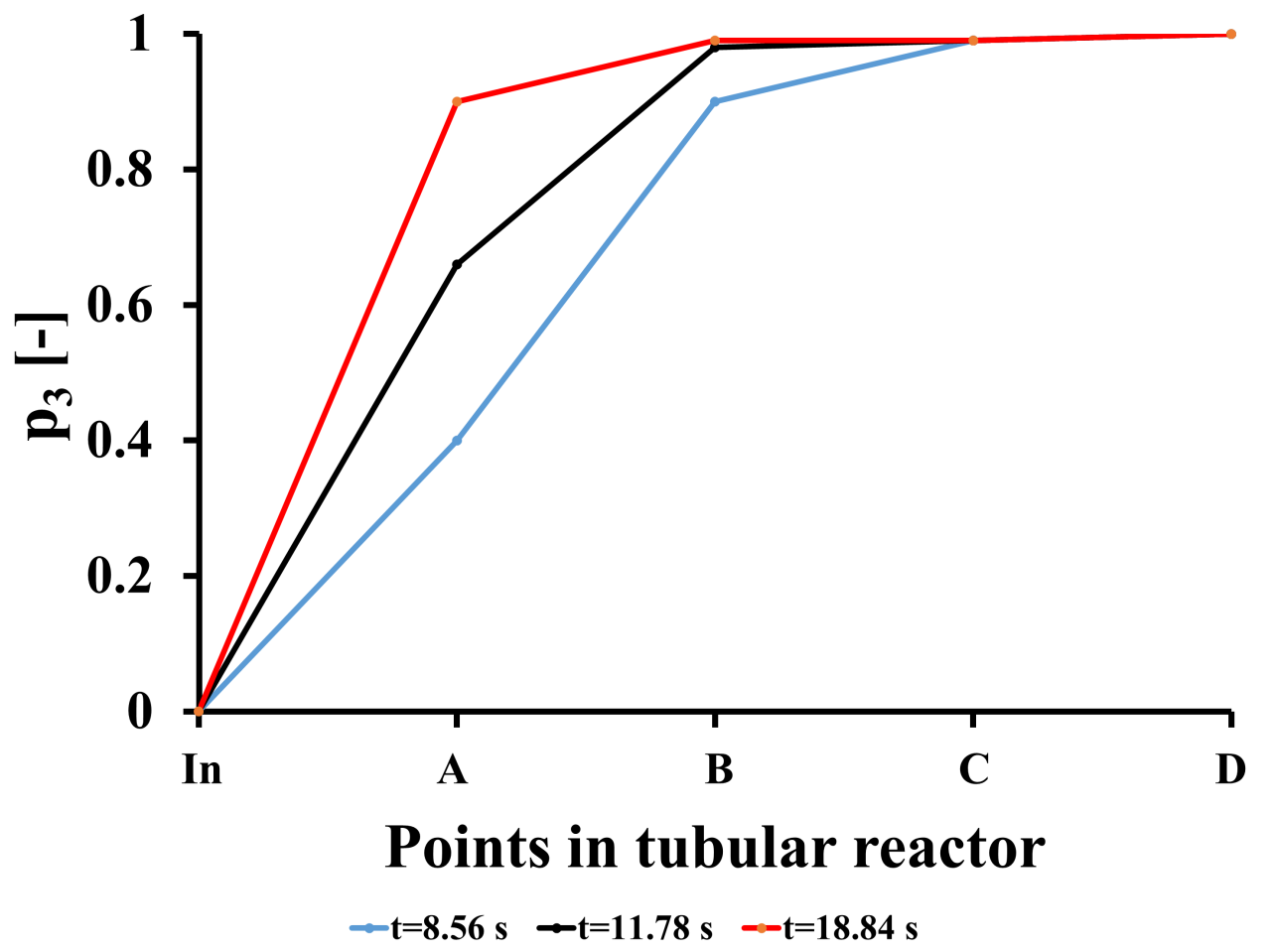

Figure 9: Mixing efficiency of the three previous studies at different points in the tubular reactor

crystallization modelling. It also provides insight into the trajectory of the crystals within the crystallizer and presents scale-up of continuous crystallizers as avenues of future research.

\section{Conclusions}

The scale-up of the ultrasound-assisted antisolvent crystallization of aspirin from ethanol water in a continuous tubular crystallizer has been studied with the use of CFD. More specifically, the acoustic effect of ultrasound was coupled with the flow field and the PBM of the antisolvent crystallization of aspirin with water, and ethanol. For modelling the crystal sizes at different experimental conditions in flow rates and API initial concentrations, the micromixing model was used with empirical expressions in the nucleation rate due to ultrasound, and in the heat generated from ultrasound and mixing. These empirical expressions were developed based on performed experiments. Comparisons between laminar flow and 
turbulent flow showed that a turbulent model should be used for capturing the crystal growth and enhanced mixing due to cavitation. Using the micromixing model in a larger diameter, the model can predict the crystal size distribution and the yield of the system at different supersaturation ratio, antisolvent content, and residence times. The model is practical in that (1) measurable input parameters have been obtained from typical crystallization protocols,

(2) a commercial package of acoustics is used in COMSOL, (3) it captures the crystal growth along the crystallizer at different conditions, and (4) it estimates and predicts the mixing efficiency. The method used in this work should be evaluated for improving the design and the scale-up of continuous crystallizers to industrially relevant throughputs.

\section{Acknowledgements}

This work was funded by the Agency for Innovation and Entrepreneurship (VLAIO) and Catalisti (grant number PIF HBC.2017.0442). S.K. acknowledges funding from the European Research Council under the ERC Starting Grant Agreement n.677169-MicroParticleControl. M.N.H. is supported by the European Union's Horizon 2020 research and innovation program under the Marie Sklodowska-Curie grant agreement No 721290 (Project website: http://cosmicetn.eu/).

\section{Abbreviations}

ASA, Acetyl-Salicylic acid, Aspirin

API, Active Pharmaceutical Ingredient

CFD, Computational Fluid Dynamics

CSD, Crystal Size Distribution

MSMPR, Mixed-Suspension, Mixed-Product Removal

PBM, Population Balance Models 


\section{Symbols}

$a_{c}$, heat transfer area per unit volume, $\left[\mathrm{m}^{2} / \mathrm{m}^{3}\right]$

$A_{\text {trans }}$, irradiating surface of the transducers $\left[\mathrm{m}^{2}\right]$

$b$, damping factor, [-]

$B_{\text {son }}$, nucleation rate from ultrasound, $\left[\# /\left(\mathrm{m}^{3} \mathrm{~s}\right)\right]$

$C$, API concentration in the solution, $\left[\mathrm{kg} / \mathrm{m}^{3}\right]$

$C_{\mu}$, constant in turbulent viscosity expression, [-]

$C_{0}$, initial API concentration, $\left[\mathrm{kg} / \mathrm{m}^{3}\right]$

$C_{1 \epsilon}$, adjustable constant, [-]

$C_{2 \epsilon}$, adjustable constant, [-]

$C_{B}$, speed of sound $[\mathrm{m} / \mathrm{s}]$

$C_{B C}$, API concentration in the boundary conditions, $\left[\mathrm{kg} / \mathrm{m}^{3}\right]$

$C_{\text {feed }}$, inlet API concentration, $\left[\mathrm{kg} / \mathrm{m}^{3}\right]$

$C_{G}$, spped of sound in borosilicate glass $[\mathrm{m} / \mathrm{s}]$

$C_{l i q}$, speed of sound in the liquid $[\mathrm{m} / \mathrm{s}]$

$C_{\text {sat }}$, solute solubility, $[\mathrm{kg} / \mathrm{kg}]$

$C V$, coefficient of variation, [-]

$C_{w}$, API concentration, $[\mathrm{kg} / \mathrm{kg}]$

$C p$, specific heat capacity of the mixture, $[\mathrm{J} /(\mathrm{kg} \mathrm{K})]$

$D$, diffusivity of the liguid, $\left[\mathrm{m}^{2} / \mathrm{s}\right]$

$D_{\text {gas }}$, thermal diffusivity of the gas, $\left[\mathrm{m}^{2} / \mathrm{s}\right]$

$D_{t}$, turbulent diffusivity of the mixture, $\left[\mathrm{m}^{2} / \mathrm{s}\right]$

$d_{i n}$, inner diameter of the tubular crystallizer, [m]

$d_{\text {trans }}$, diameter of the transducer, $[\mathrm{m}]$

$f$, frequency, $[\mathrm{Hz}]$

$f_{\phi}$, joint of all scalars, [-]

$\hat{p}$, the acoustic pressure amplitude, $[\mathrm{Pa}]$ 
$G$, crystal growth rate, $[\mathrm{m} / \mathrm{s}]$

$G_{k}$, rate of deformation

$\mathbf{G}(\mathbf{p})$, rate of change of $\mathbf{p}$ due to micromixing

$\mathbf{G}_{s}(\mathbf{p})$, eliminating term of spurious dissipation rate

in, condition in the inlet of the transducer chamber

$k$, turbulent kinetic energy, $\left[\mathrm{m}^{2} / \mathrm{s}^{2}\right]$

$k_{e f f}$, thermal conductivity, [W/(K m)]

$k_{G 1}$, empirical parameter in growth rate, $[\mathrm{m} / \mathrm{s}]$

$k_{G 2}$, empirical parameter in growth rate, $[\mathrm{J} / \mathrm{mol}]$

$k_{j 1, \text { son }}$, empirical parameter in nucleation rate, $\left[\# /\left(\mathrm{m}^{3} \mathrm{~s}\right)\right]$

$k_{j 2, \text { son }}$, empirical parameter in nucleation rate, $[\mathrm{J} / \mathrm{mol}]$

$k_{j 3, \text { son }}$, empirical parameter in nucleation rate, [-]

$k_{m}$, complex wave number, [-]

$k_{s e c, 1}$, empirical parameter in nucleation rate, $\left[\# /\left(\mathrm{m}^{2} \mathrm{~s}\right)\right]$

$k_{s e c, 2}$, empirical parameter in nucleation rate, [-]

$K_{v}$, volume shape factor, [-]

$L$, crystal size, [m]

$L_{0}$, the nuclei size, $[\mathrm{m}]$

$L_{43}$, volume-based mean crystal size, [m]

$\mathbf{M}^{\mathbf{n}}$, rate of change of $\langle\mathrm{s}\rangle_{n}$ due to micromixing

$\mathbf{M}_{\mathbf{s}}^{\mathbf{n}}$, eliminating term of spurious dissipation rate

$n$, crystal number density, $\left[\# /\left(\mathrm{m}^{3} \mathrm{~m}\right)\right]$

$N$, total number of measurements, [-]

$n_{0}$, initial number probability density function for the CSD, [\#/( $\left.\left.\mathrm{m}^{3} \mathrm{~m}\right)\right]$

$n_{b}$, number of bubbles

$n_{B C}$, probability density function for the CSD, at boundary conditions, $\left[\# /\left(\mathrm{m}^{3} \mathrm{~m}\right)\right]$

$n_{f e e d}$, the crystal size distribution at the inlet of the crystallizer, $\left[\# /\left(\mathrm{m}^{3} \mathrm{~m}\right)\right]$ 
$N_{s}$, number of all species

$p_{0}$, undisturbed pressure in the bubble, $[\mathrm{Pa}]$

$P_{c a l}$, calorimetric ultrasound power, $\left[\mathrm{J} /\left(\mathrm{m}^{3} \mathrm{~s}\right)\right]$

$P_{\text {diss }}$, power dissipated to the transducers [W]

$P_{\text {net }, U S}$, applied power of ultrasound, $[\mathrm{J} / \mathrm{s}$ ]

$p$, hydrodynamic pressure, $[\mathrm{Pa}]$

$p_{G, \text { Blake }}$, Blake threshold in the acoustic pressure, [Pa]

$p_{n}$, volume fraction of environment, [-]

$P_{\text {trans }}$, acoustic pressure at the transducer, $[\mathrm{Pa}]$

$Q_{\text {anti }}$, volume flowrate of antisolvent, $\left[\mathrm{m}^{3} / \mathrm{s}\right]$

$Q_{\text {solv }}$, volume flowrate of solvent and solute, $\left[\mathrm{m}^{3} / \mathrm{s}\right]$

$R$, ideal gas constant, $[\mathrm{J} /(\mathrm{mol} \mathrm{K})]$

$R_{0}$, equilibrium radius, [m]

$R_{c}$, consumption/source term in crystallization, $\left[\mathrm{kg} /\left(\mathrm{m}^{3} \mathrm{~s}\right)\right]$

$S$, supersaturation ratio, [-]

$S_{i n}$, supersaturation ratio in the inlet of the transducer, [-]

$\langle s\rangle_{n}$, weighted concentration of mean composition of scalars in mode $n$

$t$, time, $[\mathrm{s}]$

$T$, temperature of the mixture, $[\mathrm{K}]$

$T_{B C}$, temperature in the boundary conditions, $[\mathrm{K}]$

$T_{i n}$, inlet temperature of the mixture, $[\mathrm{K}]$

$T_{0}$, initial temperature of the mixture in the crystallizer, $[\mathrm{K}]$

$T_{w}$, temperature of the cooling water, $[\mathrm{K}]$

$u$, fluid velocity, $[\mathrm{m} / \mathrm{s}]$

$U_{c}$, overall heat transfer coefficient, $\left[\mathrm{J} /\left(\mathrm{m}^{2} \mathrm{~s} \mathrm{~K}\right)\right]$

$V$, volume of crystals over volume of the slurry, $\left[\mathrm{m}^{3} / \mathrm{m}^{3}\right]$

$w$, antisolvent content, [-] 
$\mathrm{x}, \mathrm{x}$ - coordinate

$y, y$ - coordinate

z, z- coordinate

$\beta$, cavity volume fraction, [-]

$\gamma_{f}$, adiabatic factor, [-]

$\Delta H_{\text {mix }}$, enthalpy of mixing, $[\mathrm{J} / \mathrm{kg}]$

$\epsilon$, turbulent kinetic energy dissipation rate $\left[\mathrm{m}^{2} / \mathrm{s}^{2}\right]$

$\mu$, viscosity of the medium, $[\mathrm{kg} /(\mathrm{m} \mathrm{s})]$

$\mu_{i}, i^{t h}$ moment of the size distribution, $\left[\mathrm{m}^{i} / \mathrm{m}^{3}\right]$

$\mu_{t}$, turbulent viscosity, $[\mathrm{kg} /(\mathrm{m} \mathrm{s})]$

$\xi$, mixture fraction, [-]

$\rho$, mixture density, $\left[\mathrm{kg} / \mathrm{m}^{3}\right]$

$\rho_{B}$, bulk density $\left[\mathrm{kg} / \mathrm{m}^{3}\right]$

$\rho_{c}$, crystal density, $\left[\mathrm{kg} / \mathrm{m}^{3}\right]$

$\rho_{G}$, density of borosilicate glass $\left[\mathrm{kg} / \mathrm{m}^{3}\right]$

$\sigma$, surface tension of the liquid, $[\mathrm{N} \cdot \mathrm{m}]$

$\sigma_{\epsilon}$, adjustable constant, [-]

$\sigma_{k}$, adjustable constant, [-]

$\tau$, the stress tensor, $\left[\mathrm{kg} /\left(\mathrm{m} \mathrm{s}^{2}\right)\right]$

$\Phi$, complex dimensionless parameter, [-]

$\phi_{\alpha}$, composition of scalar $\alpha$

$\chi$, dimensionless parameter, [-]

$\omega$, ultrasound frequency, $[1 / \mathrm{s}]$

$\omega_{0}$, resonant frequency, $[\mathrm{rad} / \mathrm{s}]$ 


\section{References}

(1) Gao, Z.; Rohani, S.; Gong, J.; Wang, J. Recent developments in the crystallization process: Toward the pharmaceutical industry. Engineering 2017, 3, 343-353.

(2) Zhang, D.; Xu, S.; Du, S.; Wang, J.; Gong, J. Progress of pharmaceutical continuous crystallization. Engineering 2017, 3, 354-364.

(3) Yang, X.; Acevedo, D.; Mohammad, A.; Pavurala, N.; Wu, H.; Brayton, A. L.; Shaw, R. A.; Goldman, M. J.; He, F.; Li, S.; Fisher, R. J.; O’Connor, T. F.; Cruz, C. N. Risk considerations on developing a continuous crystallization system for carbamazepine. Org. Process Res. Dev. 2017, 21, 1021-1033.

(4) Lai, T.-T. C.; Cornevin, J.; Ferguson, S.; Li, N.; Trout, B. L.; Myerson, A. S. Control of polymorphism in continuous crystallization via mixed suspension mixed product removal systems cascade design. Cryst. Growth Des. 2015, 15, 3374-3382.

(5) Baxendale, I. R.; Braatz, R. D.; Hodnett, B. K.; Jensen, K. F.; Johnson, M. D.; Sharratt, P.; Sherlock, J.-P.; Florence, A. J. Achieving continuous manufacturing: Technologies and approaches for synthesis, workup, and isolation of drug substance. May 20-21, 2014 Continuous Manufacturing Symposium. J. Pharm. Sci. 2015, 104, 781-791.

(6) Dodds, J.; Espitalier, F.; Louisnard, O.; Grossier, R.; David, R.; Hassoun, M.; Baillon, F.; Gatumel, C.; Lyczko, N. The effect of ultrasound on crystallisation-precipitation processes: Some examples and a new segregation model. Part. Part. Syst. Charact. 2007, 24, 18-28.

(7) Fernandez Rivas, D.; Kuhn, S. Synergy of Microfluidics and Ultrasound. Top. Curr. Chem. 2016, 374, 70-99.

(8) Kiss, A. A.; Geertman, R.; Wierschem, M.; Skiborowski, M.; Gielen, B.; Jordens, J.; 
John, J. J.; Van Gerven, T. Ultrasound-assisted emerging technologies for chemical processes. J. Chem. Technol. Biotechnol. 2018, 93, 1219-1227.

(9) Fatemi, N.; Dong, Z.; Van Gerven, T.; Kuhn, S. Microbubbles as heterogeneous nucleation sites for crystallization in continuous microfluidic devices. Langmuir 2018, 35, 60-69.

(10) Jiang, M.; Papageorgiou, C. D.; Waetzig, J.; Hardy, A.; Langston, M.; Braatz, R. D. Indirect ultrasonication in continuous slug-flow crystallization. Cryst. Growth Des. 2015, 15, 2486-2492.

(11) Rossi, D.; Jamshidi, R.; Saffari, N.; Kuhn, S.; Gavriilidis, A.; Mazzei, L. Continuousflow sonocrystallization in droplet-based microfluidics. Cryst. Growth Des. 2015, 15, $5519-5529$.

(12) Jordens, J.; Canini, E.; Gielen, B.; Van Gerven, T.; Braeken, L. Ultrasound assisted particle size control by continuous seed generation and batch growth. Crystals 2017, 7, 195-214.

(13) Gielen, B.; Jordens, J.; Janssen, J.; Pfeiffer, H.; Wevers, M.; Thomassen, L.; Braeken, L.; Van Gerven, T. Characterization of stable and transient cavitation bubbles in a milliflow reactor using a multibubble sonoluminescence quenching technique. Ultrason. Sonochem. 2015, 25, 31-39.

(14) Jamshidi, R.; Rossi, D.; Saffari, N.; Gavriilidis, A.; Mazzei, L. Investigation of the effect of ultrasound parameters on continuous sonocrystallization in a millifluidic device. Cryst. Growth Des. 2016, 16, 4607-4619.

(15) Kordylla, A.; Krawczyk, T.; Tumakaka, F.; Schembecker, G. Modeling ultrasoundinduced nucleation during cooling crystallization. Chem. Eng. Sci. 2009, 64, 16351642. 
(16) Nalesso, S.; Bussemaker, M. J.; Sear, R. P.; Hodnett, M.; Lee, J. A Review on Possible Mechanisms of Sonocrystallisation in Solution. Ultrason. Sonochem. 2019,

(17) Sivabalan, R.; Gore, G.; Nair, U.; Saikia, A.; Venugopalan, S.; Gandhe, B. Study on ultrasound assisted precipitation of CL-20 and its effect on morphology and sensitivity. J. Hazard. Mater. 2007, 139, 199-203.

(18) Ramisetty, K. A.; Pandit, A. B.; Gogate, P. R. Ultrasound-assisted antisolvent crystallization of benzoic acid: Effect of process variables supported by theoretical simulations. Ind. Eng. Chem. Res. 2013, 52, 17573-17582.

(19) Hussain, M. N.; Jordens, J.; John, J.; Braeken, L.; Van Gerven, T. Enhancing pharmaceutical crystallization in a flow crystallizer with ultrasound: Anti-solvent crystallization. Ultrasonics sonochemistry 2019, 59, 104743.

(20) Ramkrishna, D., Ed. Population balances: Theory and applications to particulate systems in engineering; Elsevier: San Diego, CA, 2000.

(21) Su, Q.; Benyahia, B.; Nagy, Z. K.; Rielly, C. D. Mathematical modeling, design, and optimization of a multisegment multiaddition plug-flow crystallizer for antisolvent crystallizations. Org. Process Res. Dev. 2015, 19, 1859-1870.

(22) Su, Q.; Nagy, Z. K.; Rielly, C. D. Pharmaceutical crystallisation processes from batch to continuous operation using MSMPR stages: Modelling, design, and control. Chem. Eng. Process. 2015, 89, 41-53.

(23) Jung, W.; Park, J.; Lee, W.; Lee, J.; Koo, K.; Oh, M. Scale-Up of a Crystallizer for Production of Nano-Sized Energetic Materials. Chemical Engineering \& Technology 2016, 39, 1309-1316.

(24) Öner, M.; Bach, C.; Tajsoleiman, T.; Molla, G. S.; Freitag, M. F.; Stocks, S. M.; 
Abildskov, J.; Krühne, U.; Sin, G. Computer Aided Chemical Engineering; Elsevier, 2018; Vol. 44; pp 181-186.

(25) Peeters, D.; Huyskens, P. Endothermicity or exothermicity of water/alcohol mixtures. J. Mol. Struct. 1993, 300, 539-550.

(26) Savvopoulos, S. V.; Hussain, M. N.; Jordens, J.; Waldherr, S.; Van Gerven, T.; Kuhn, S. A Mathematical Model of the Ultrasound-Assisted Continuous Tubular Crystallization of Aspirin. Cryst. Growth Des. 2019, 19, 5111-5122.

(27) Jordens, J.; Honings, A.; Degrève, J.; Braeken, L.; Van Gerven, T. Investigation of design parameters in ultrasound reactors with confined channels. Ultrasonics sonochemistry 2013, 20, 1345-1352.

(28) da Rosa, C. A.; Braatz, R. D. Multiscale modeling and simulation of macromixing, micromixing, and crystal size distribution in radial mixers/crystallizers. Ind. Eng. Chem. Res. 2018, 57, 5433-5441.

(29) Pope, S. B. Turbulent Flows; Cambridge University Press, 2000; p 358-386.

(30) Marchisio, D.; Barresi, A.; Fox, R. Simulation of turbulent precipitation in a semi-batch Taylor-Couette reactor using CFD. AIChE J. 2001, 47, 664-676.

(31) Marchisio, D. L.; Fox, R. O.; Barresi, A. A.; Baldi, G. On the comparison between presumed and full PDF methods for turbulent precipitation. Ind. Eng. Chem, Res. 2001, 40, 5132-5139.

(32) Marcfflsio, D.; Fox, R.; Barresi, A.; Garbero, M.; Baldi, G. On the simulation of turbulent precipitation in a tubular reactor via computational fluid dynamics (CFD). Chem. Eng. Res. Des. 2001, 79, 998-1004.

(33) Kwon, J. S.-I.; Nayhouse, M.; Orkoulas, G.; Christofides, P. D. Crystal shape and size 
control using a plug flow crystallization configuration. Chem. Eng. Sci. 2014, 119, 30-39.

(34) Lindenberg, C.; Krättli, M.; Cornel, J.; Mazzotti, M.; Brozio, J. Design and optimization of a combined cooling/antisolvent crystallization process. Cryst. Growth Des. 2008, 9, 1124-1136.

(35) Koopmans, L. H.; Owen, D. B.; Rosenblatt, J. Confidence intervals for the coefficient of variation for the normal and log normal distributions. Biometrika 1964, 51, 25-32.

(36) PSE, gPROMS Advanced User Guide; Process Systems Enterprise: London, UK, 2004; p 37.

(37) Jordens, J.; Appermont, T.; Gielen, B.; Van Gerven, T.; Braeken, L. Sonofragmentation: Effect of ultrasound frequency and power on particle breakage. Cryst. Growth Des. 2016, 16, 6167-6177. 